\title{
Loss of imprinting of IGF2 correlates with hypermethylation of the HI 9 differentially methylated region in hepatoblastoma
}

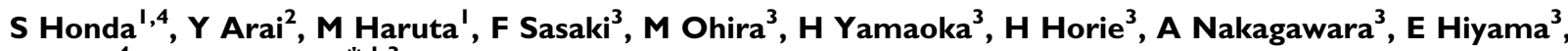 \\ S Todo ${ }^{4}$ and $Y$ Kaneko*, I,3
}

'Department of Cancer Diagnosis, Saitama Cancer Center, Research Institute for Clinical Oncology, 818 Komuro, Ina, Saitama 362-0806, Japan; ${ }^{2}$ Cancer Genomics Project, National Cancer Center Research Institute, Chuo-Ku, Tokyo 104-0045, Japan; 3apanese Study Group for Pediatric Liver Tumor (IPLT),

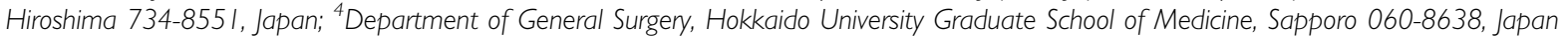

\begin{abstract}
IGF2, a maternally imprinted foetal growth factor gene, is implicated in many childhood tumours including hepatoblastoma (HB); however, the genetic and epigenetic alterations have not comprehensively been studied. We analysed the methylation status of the HI 9 differentially methylated region (DMR), loss of heterozygosity (LOH) and allelic expression of IGF2 in 54 HB tumours, and found that 12 tumours (22\%) with $\mathrm{LOH}, 9$ (I $7 \%$ ) with loss of imprinting (LOI) and 33 (6I\%) with retention of imprinting (ROI). Biallelic and monoallelic IGF2 expressions correlated with hypermethylation and normal methylation of HI 9 DMR, respectively, in two tumours with LOI and seven tumours with ROI. Quantitative RT-PCR analysis showed minimal expression of HI 9 mRNA and substantial expression of IGF2 mRNA in tumours with LOH or LOI, and substantial expression of both HI 9 and IGF2 mRNAs in tumours with ROI. Increased IGF2 expression with predominant embryonic P3 transcript was found in the majority of HBs with ROI and foetal livers. In contrast to the earlier reports, our findings suggest that the disruption of the enhancer competition model reported in Wilms' tumour may also occur in HB. Both frequencies of $\mathrm{LOH}$ and $\mathrm{LOI}$ seem to be lower in HB than in Wilms' tumour, reflecting the different tissue origins.

British Journal of Cancer (2008) 99, I89I-1899. doi:| 0.1038/sj.bjc.6604754 www.bjcancer.com

Published online 28 October 2008

(c) 2008 Cancer Research UK
\end{abstract}

Keywords: hepatoblastoma; IGF2; HI9; loss of heterozygosity; loss of imprinting

Hepatoblastoma (HB) is a rare malignant neoplasm of the liver, with an incidence of 0.5-1.5 per million children (Perilongo and Shafford, 1999). Remarkable progress in clinical outcome has been achieved in the past 20 years because of advances in chemotherapy and surgical procedures; however, the mortality rate remains $20-$ $30 \%$ and treatment results in patients in advanced stages who are refractory to standard preoperative chemotherapy regimens are unsatisfactory (Perilongo et al, 2000; Fuchs et al, 2002). To improve the mortality of these patients, innovative treatment based on a specific molecular target is needed. The molecular mechanism involved in the development and progression of $\mathrm{HB}$ includes overexpression of insulin-like growth factor-II (IGF2) (Li et al, 1998b; Gray et al, 2000; Hartmann et al, 2000), downregulation of RASSF1A by promoter hypermethylation (Sugawara et al, 2007; Honda et al, 2008) and alterations of genes in the Wnt signalling pathway; most notably, the high incidence of CTNNB1 (catenin, $\beta 1$ ) mutation (Koch et al, 1999; Taniguchi et al, 2002).

IGF2 is a maternally imprinted gene and encodes a foetal peptide hormone that regulates cellular proliferation and differentiation (Foulstone et al, 2005). IGF2 has four promoter regions and P3 is the most active promoter in the foetal liver, followed

*Correspondence: Dr Y Kaneko; E-mail: kaneko@cancer-c.pref.saitama.jp Received 24 June 2008; revised 30 September 2008; accepted I October 2008; published online 28 October 2008 by $\mathrm{P} 2$ and $\mathrm{P} 4$ promoters (Li et al, 1998a). PLAG1 encodes a developmentally regulated transcription factor, which positively regulates $I G F 2$ through binding the $\mathrm{P} 3$ promoter region. Although IGF2 is downregulated in normal tissues after birth, except for liver tissues, it is overexpressed in a wide variety of childhood and adult cancers and serves as a tumour enhancer through autocrine and paracrine mechanisms (Toretsky and Helman, 1996). IGF2 has been studied extensively over the past decade as a key molecule involving $\mathrm{HB}$ and Wilms' tumour (WT) pathogenesis.

The allelic expression of IGF2 is regulated by the methylation status of the sixth CTCF (CCCTC-binding factor) site in the H19 differentially methylated region (DMR) that represents the parental origin of the IGF2 allele; whereas the paternal CTCF6 allele is methylated, the maternal allele is unmethylated in normal tissues (Bell and Felsenfeld, 2000; Hark et al, 2000; Takai et al, 2001). Using the enhancer competition model, IGF2 and H19 promoters compete on the same chromosome for a shared enhancer, and access of the maternal IGF2 allele to this enhancer is blocked by H19 DMR when unmethylated because of the insulator activity of CTCF binding to unmethylated H19 DMR (Bell and Felsenfeld, 2000; Hark et al, 2000). It has been proved in many WTs that aberrant methylation of the maternal CTCF6 prevents the insulator binding and leads to loss of imprinting (LOI), resulting in the overexpression of IGF2 (Steenman et al, 1994; Ravenel et al, 2001). Although LOI of IGF2 was reported in HB, the mechanism of LOI, the concurrent overexpression of IGF2 mRNA and loss of 
H19 mRNA expression are uncertain because of the limited number of HB tumours examined and the low frequency of the heterozygous IGF2 polymorphic site in general populations (Davies, 1993; Montagna et al, 1994; Rainier et al, 1995; Li et al, 1995, 1998b; Fukuzawa et al, 1999; Gray et al, 2000; Hartmann et al, 2000; Ross et al, 2000; Albrecht et al, 2004; Suzuki et al, 2008), and some investigators stated earlier that the mechanisms of IGF2 upregulation by LOI found in WT do not apply to $\mathrm{HB}$ ( $\mathrm{Li}$ et al, 1995; Hartmann et al, 2000).

Loss of imprinting was reported in $32-38 \%$ of WTs (Ravenel et al, 2001; Fukuzawa et al, 2004; Yuan et al, 2005), and loss of heterozygosity (LOH), leading to uniparental disomy (UPD) of the paternal IGF2, was reported in $36-50 \%$ of WTs (Grundy et al, 1996; Fukuzawa et al, 2004; Yuan et al, 2005). In HB, although LOH of IGF2 was reported in 20-30\%, the incidence of LOI of IGF2 was uncertain because each series included only a small number of HB tumours. In addition, it is also uncertain whether the same mechanism of LOI is involved in both WT and HB tumorigeneses because the methylation status of H19 DMR in HB has rarely been examined (Li et al, 1995, 1998b; Fukuzawa et al, 1999).

To determine whether the alterations of IGF2 and H19 loci identified in WT are also found in HB, we examined the LOI and LOH status of IGF2 using combined bisulphite restriction assay (COBRA) of the CTCF6 region that can determine the methylation status of H19 DMR more efficiently than the method using methylation-specific restriction enzymes and Southern blot in $54 \mathrm{HB}$ tumours. In addition, we evaluated promoter-specific IGF2 transcripts, the methylation status of IGF2 promoters and PLAG1 mRNA expression. Our results showed that the genetic and epigenetic alterations in the IGF2-H19 region with elevated expression of IGF2 mRNA identified in WTs were also found in the great majority of $\mathrm{HB}$ tumours, although the incidences of $\mathrm{LOH}$ and LOI may be lower in HBs than in WTs.

\section{MATERIALS AND METHODS}

\section{Patients and samples}

Tumour tissues were obtained from 54 Japanese children with HB, and adjacent normal liver tissues were available from 5 patients. Eighteen tumour and five matched normal liver specimens were supplied by the Tissue Bank of the Japanese Study Group for Pediatric Liver Tumour (JPLT) (Matsunaga et al, 2004), and 36 were supplied by institutions affiliated with Saitama Cancer Center. DNA and RNA were extracted from tumour and normal tissue samples that were immediately frozen after the resection or on arrival at the centre. The median age of the 54 patients at diagnosis was 18 months (range, 1-156 months). None of patients had the Beckwith-Wiedemann syndrome or a family history of familial polyposis coli. A total of 14 and 37 tumours were obtained before and after chemotherapy, respectively, and the chemotherapy status was unknown in the other 3 tumours. Pathologists in each institution and/or the JPLT pathology panel made the diagnosis of $\mathrm{HB}$ and verified that each sample contained $70 \%$ or more tumour cells. Informed consent was obtained from the parents, and the study design was approved by the ethics committee of Saitama Cancer Center.

\section{COBRA of the CTCF6 site at H19 DMR}

We performed COBRA to determine the methylation status of the CTCF6 binding site at H19 DMR, as described earlier (Watanabe et al, 2007). COBRA of CTCF6 showed that the mean methylation percentage \pm 2 s.d. of five normal livers was $52.8 \pm 15.0 \%$, and we defined more than the mean percentage +2 s.d. as the hypermethylated state.

\section{LOH analysis of IGF2}

High-resolution single nucleotide polymorphism (SNP) array, Affymetrix Mapping 50K-Xba array (Affymetrix, Santa Clara, CA, USA), was used to analyse chromosomal aberrations of $11 \mathrm{p} 15.5$ where IGF2 resides. Genomic DNA in 43 of 54 tumours and 2 cell lines was assayed according to the manufacturer's protocol, and the genomic status of IGF2 was determined as described earlier (Haruta et al, 2008).

\section{Allelic expression analysis of IGF2 and quantitative real- time reverse transcription-PCR analysis of IGF2 and $\mathrm{H} 19$ mRNA}

The ApaI/AvaII polymorphic site in exon 9 of $I G F 2$ was used to evaluate the allelic expression of IGF2 mRNA in 21 tumours whose RNA was available for this study, as described earlier (Watanabe et al, 2006). Quantitative real-time reverse transcription-PCR was performed to evaluate the total IGF2 and H19 mRNA levels in 20 tumour tissues, $2 \mathrm{HB}$ cell lines (HuH6 and HepG2), foetal liver total RNA pooled from 34 foetuses (Clontech, Ohtsu, Japan) and 3 normal liver tissues adjacent to $\mathrm{HB}$; the age of the patients was 16 , 24 or 26 months. Of the 20 tumours, 3 and 16 were obtained before and after chemotherapy, respectively, and the chemotherapy status was unknown in 1. The primers and TaqMan probes used for IGF2 and $H 19$ mRNA were described earlier (Watanabe et al, 2007; Haruta et al, 2008). The expression of IGF2 and H19 mRNAs was normalised with GAPDH.

\section{Methylation-specific PCR and bisulphite sequencing analysis of IGF2 promoter regions}

Genomic DNA from tumour and normal liver samples was treated with sodium bisulphite (Herman et al, 1996), and the methylation status of the P2-P4 promoter regions of IGF2 was analysed by methylation-specific PCR (MSP), as described earlier (Beeghly et al, 2007). Polymerase chain reaction products were run on $2 \%$ agarose gels and visualised after staining with ethidium bromide. We confirmed the results of MSP analysis of P3 promoter by bisulphite sequencing of eight or more subcloned plasmids.

\section{Semiquantitative RT - PCR analysis of promoter-specific transcripts of IGF2 and PLAG1}

$\mathrm{P} 1$ and $\mathrm{P} 3$ promoter specific expressions of IGF2 mRNA were analysed using the primer sets described elsewhere ( $\mathrm{Lu}$ et al, 2006). The primer sequences for P2-specific transcript were derived from exons 4 and 5: forward, 5'-CCCTCAGGACGTGGACAG-3'; reverse, 5'-GTGCGTTGGACTTGCATAGA-3'; and the primer sequences for P4-specific transcript were derived from exons 7, 8 and 9: forward, 5'-CGAGCCTTCTGCTGAGCTAC-3'; reverse, 5'-CGGAAACAGCA CTCCTCAAC- $3^{\prime}$. PLAG1 mRNA expression was analysed using the following primer sets: forward, $5^{\prime}$-AACGTAAGCGTGGTGAAACC-3'; reverse, 5'-TGCCACATTCTTCGCACTTA-3' (Zatkova et al, 2004). Polymerase chain reaction products were run on polyacrylamide gels and visualised after ethidium bromide staining. The intensity of each band was examined using a fluorescence image analyser, FLA-3000G (Fujifilm, Tokyo, Japan). Dividing the intensity of the target transcript by that of GAPDH calculated the level of each transcript.

\section{Mutation analysis of the CTNNB1 gene}

To detect point mutations and deletions of the CTNNB1 gene, genomic DNA from each tumour sample was amplified using two sets of primers, F1, $5^{\prime}$-TGGCTATCATTCTGCTTTTCTTG- $3^{\prime}$ and R1, 5'-CTCTTTTCTTCACCACAACATTTT-3', and BCAT-3, 5'-AA 
AATCCAGCGTGGACAATGG- $3^{\prime}$ and BCAT-4, 5'-TGTGGCAAGTT CTGCATCATC-3', respectively (Koch et al, 1999; Satoh et al, 2003). The PCR products were either directly sequenced or inserted into a vector (pGEM (R)-T Easy Vector System (Promega, Madison, WI, USA)), and six or more clones were sequenced.

\section{Statistical analysis}

Student's $t$-test or Welch's $t$-test compared mRNA levels of IGF2 and $\mathrm{H} 19$ between tumours with or without IGF2 alterations or other characteristics and the levels of IGF2 promoter-specific transcripts between tumours with or without PLAG1 mRNA expression. We also assessed the association between total IGF2 mRNA levels and P2-, P3- or P4-specific IGF2 mRNA levels by determining the Spearman rank correlation coefficient and associated $P$-value. Differences in the incidence of tumours with unmethylated P3 promoter were examined between tumours with hypermethylated H19 DMR and tumours with normally methylated $H 19$ DMR by the $\chi^{2}$ test. Differences in the incidences of tumours with CTNNB1 mutation were examined between any two of three groups of tumours classified on the basis of the IGF2 status by the $\chi^{2}$ test.

\section{RESULTS}

Methylation status of the CTCF6 binding site at H19 DMR, LOH analysis using SNP array and allelic expression analysis of IGF2

Combined bisulphite restriction assay showed that 21 and 33 tumours had hypermethylation and normal methylation at CTCF6, indicating $\mathrm{LOH}$ or LOI and retention of IGF2 imprinting (ROI), respectively (Table 1 and Figure 1). Single nucleotide polymorphism array analysis was performed in 43 of 54 tumours; all 21 tumours with hypermethylated CTCF6 and 22 of 33 tumours with normally methylated CTCF6. Combined results of both analyses indicated that 12 tumours had LOH (10 hypermethylated CTCF6 and UPD 2 hypermethylated CTCF6 and hemizygous 11p15 deletion), 9 had LOI (hypermethylated CTCF6 and retention of heterozygosity (ROH)) and 22 had ROI (normally methylated CTCF6 and ROH). Of 21 tumours whose RNA was available, 9 and 12 tumours had heterozygous and homozygous ApaI/AvaII sites in exon 9 of IGF2, respectively. Of the nine heterozygous tumours, seven showed monoallelic expression of IGF2, indicating ROI, and two showed biallelic expression of IGF2, indicating LOI, and the results were consistent with those examined by COBRA and SNP array analyses (Table 1). From these findings, 11 tumours with normally methylated CTCF6, in which SNP array analysis was not performed, were classified as those with ROI. Thus, combined results of COBRA, SNP array and allelic expression analyses showed 12 tumours with $\mathrm{LOH}, 9$ tumours with LOI and 33 tumours with ROI. In addition, one cell line (HuH6) had LOI, and the other (HepG2) had LOH (UPD) of IGF2.

The mean age was compared between any two of three groups of patients (i.e., LOH, LOI or ROI) by Student's $t$-test. There was no difference in the mean age between any two of the three groups of patients.

\section{Correlation between IGF2 and H19 mRNA levels and the IGF2 status (LOH, LOI or ROI)}

Quantitative real-time reverse transcription-PCR analysis showed that although 15 of 20 tumours had a higher level of IGF2 mRNA than normal liver tissues, 15 of 20 tumours had a lower level of H19 mRNA than normal liver tissues (Table 1 and Figure 2). All 3 tumours with UPD, 1 of 1 with 11 p 15 loss, 1 of 3 with LOI and 10 of 13 with ROI, expressed higher levels of IGF2 mRNA than normal liver tissues. There was no significant difference in IGF2 mRNA levels between 3 tumours with UPD or 7 tumours with IGF2 alterations; that is UPD, $11 \mathrm{p} 15$ loss or LOI, and 13 tumours with ROI. In contrast, 7 tumours with IGF2 alterations expressed very low levels of $H 19$ mRNA, whereas 11 of 13 tumours with ROI expressed a substantial amount of $H 19$ mRNA; 2 tumours (nos. 25 and 27) with ROI expressed very low levels of H19 mRNA. $H 19$ mRNA levels were higher in $13 \mathrm{HB}$ tumours with ROI than in $7 \mathrm{HB}$ tumours with IGF2 alterations $(P<0.01$ by Welch's $t$-test). Although HepG2 with UPD had a higher level of IGF2 mRNA than normal liver tissues, HuH6 with LOI had a very low level of IGF2 mRNA. H19 mRNA levels were very low in both cell lines.

\section{Semiquantitative RT - PCR analysis of promoter-specific IGF2 transcripts}

Because the IGF2 gene has four kinds of promoters, promoterspecific IGF2 transcripts were analysed to determine the usage of each promoter. Representative results of the $\mathrm{P} 3$ transcript are shown in Figure 3A. All 20 tumours showed undetectable or lower levels of P1 transcripts than 3 normal liver tissues. The levels of P2, P3 and P4 transcripts were higher in 13,15 and 10 of the 20 tumours, respectively, than those of normal liver tissues. Polymerase chain reaction cycle numbers to obtain visible levels of PCR products were 40 for P2 transcripts, 30 for P3 transcripts and 35 for P4 transcripts, indicating that the amounts of P3 transcripts were high, those of P2 transcripts were low and those of P4 transcripts were intermediate. The Spearman correlation coefficient analysis showed that the expression levels of the P2, P3 and P4 transcripts correlated with the levels of total IGF2 mRNA (P2, $r S=0.730 ; \mathrm{P} 3, r S=0.773$ and $\mathrm{P} 4, r S=0.646$ ) (Figure $3 \mathrm{~B}$ and $\mathrm{C}$; data for the $\mathrm{P} 2$ and $\mathrm{P} 4$ transcripts are not shown).

\section{The methylation status of IGF2 promoters and its correlation with the levels of promoter-specific transcripts}

In the MSP analysis of each promoter, the $\mathrm{P} 2$ promoter region was partially methylated in 19 tumours and normal liver tissues and the $\mathrm{P} 4$ promoter region was unmethylated in all 20 tumours and normal liver tissues. Therefore, the methylation status of $\mathrm{P} 2$ or $\mathrm{P} 4$ promoter region was not correlated with the expression level of P2or P4-specific transcripts. The P3 promoter region was partially methylated in 11 tumours, HuH6 and normal liver tissues and unmethylated in 9 tumours and HepG2 (Table 1, Figure 4A and B). The results of MSP analysis in one tumour (no. 1) and HuH6 were confirmed by bisulphite sequencing (Figure 4C). Nine tumours with the unmethylated P3 promoter had higher levels of P3 transcripts than 11 tumours with the partially methylated P3 promoter $(P=0.005)$ (Figure $4 \mathrm{D})$. The P3 promoter was unmethylated in 5 of 7 tumours with IGF2 alterations; UPD, $11 \mathrm{p} 15$ loss or LOI, but in 4 of 13 tumours with ROI. Thus, the incidence of tumours with unmethylated P3 promoter tended to be higher in tumours with hypermethylated H19 DMR than in tumours with normally methylated $H 19$ DMR $(P=0.1)$.

\section{Semiquantitative RT - PCR analysis of PLAG1 mRNA}

PLAG1 positively regulates IGF2, and its expression was detected in 12 tumours, foetal liver RNA and 2 cell lines, but not in 8 tumour and 3 normal liver tissues (Table 1 and Figure 5). The 12 tumours with PLAG1 mRNA expression showed higher levels of P4-specific IGF2 transcripts $(P=0.01)$ and tended to show higher levels of P3-specific IGF2 transcripts $(P=0.051)$ than the 8 tumours without PLAG1 expression. There was no significant difference in P2- or P1-specific transcript levels between tumours with and without PLAG1 mRNA expression. 
Table I Genetic and epigenetic status of the IGF2-HI9 region in 54 hepatoblastoma tumours

\begin{tabular}{|c|c|c|c|c|c|c|c|c|c|c|c|c|c|c|c|c|c|}
\hline $\begin{array}{l}\text { Patients } \\
\text { number }\end{array}$ & Age $^{a} /$ sex & Chemo $^{b}$ & $\begin{array}{l}\text { \%methyl } \\
\text { CTCF6 }^{c}\end{array}$ & IIpI5 SNPd & Apal site ${ }^{e}$ & $\begin{array}{l}\text { IGF2 } \\
\text { RT-PCR }\end{array}$ & IGF2 status ${ }^{f}$ & $\begin{array}{c}\text { IGF2 } \\
\text { mRNA }\end{array}$ & $P I E^{g}$ & $\mathbf{P} 2 \mathbf{M}^{\mathrm{h}}$ & P2E & P3M & P3E & P4E & $\begin{array}{c}\text { HI9 } \\
\text { mRNA }\end{array}$ & $\begin{array}{l}\text { PLAGI } \\
\text { mRNA }\end{array}$ & $\begin{array}{l}\text { CTNNBI } \\
\text { status }^{i}\end{array}$ \\
\hline I & $48 / F$ & + & 82.8 & UPD & Homo & ND & UPD & 11.3 & 0.6 & $M U$ & 17.7 & $U$ & 7 & 3.1 & 0 & + & $M$ \\
\hline 2 & $5 / M$ & - & 93.4 & UPD & Homo & ND & UPD & 3.9 & 0 & $M U$ & 0 & U & 2.1 & 0.9 & 0 & - & $M$ \\
\hline 3 & $24 / M$ & + & 76.7 & UPD & Homo & ND & UPD & 3.2 & 0 & $M U$ & 2.4 & $M U$ & 2.3 & 1.2 & 0 & + & $M$ \\
\hline $4-10$ & $5-96 / \mathrm{Mb}, \mathrm{FI}$ & $+6,-1$ & $72-90$ & UPD & ND & ND & UPD & ND & ND & ND & ND & ND & ND & ND & ND & ND & M4, N3 \\
\hline 11 & $27 / M$ & + & 87.8 & Loss chr II & Homo & ND & Loss & 6.1 & 0 & $M U$ & 2.3 & $U$ & 4.4 & 1.3 & 0 & + & M \\
\hline 12 & $24 / M$ & + & 81.9 & Loss chr II & ND & ND & Loss & ND & ND & ND & ND & ND & ND & ND & ND & ND & $M$ \\
\hline 13 & $12 / F$ & + & 91.4 & $\mathrm{ROH}$ & Homo & ND & LOI (m) & 9.7 & 0 & U & 1.1 & U & 2.3 & 0.6 & 0 & - & ND \\
\hline 14 & $16 / M$ & - & 86.1 & $\mathrm{ROH}$ & Homo & ND & LOI (m) & 1 & 0 & $M U$ & 0.3 & $U$ & 1.3 & 0.9 & 0 & - & ND \\
\hline 15 & $26 / F$ & + & 83.1 & $\mathrm{ROH}$ & Hetero & LOI & LOI $(m, p)$ & 0.8 & 0 & $\mathrm{MU}$ & 0.4 & $M U$ & 0.6 & 0.9 & 0 & - & $M$ \\
\hline 16 & $24 / M$ & + & 70.9 & $\mathrm{ROH}$ & Hetero & LOI & LOI $(m, p)$ & ND & ND & ND & $N D$ & ND & ND & ND & ND & ND & M \\
\hline$|7-2|$ & I2-84/M4, Fl & $+1,-3$, UKI & $7|-9|$ & $\mathrm{ROH}$ & ND & ND & LOI (m) & ND & ND & ND & ND & ND & ND & ND & ND & ND & $M 3, N 2$ \\
\hline 22 & $12 / F$ & + & 52.5 & ND & Homo & ND & $\mathrm{ROI}(\mathrm{m})$ & 9.2 & 0.8 & $M U$ & 8.4 & $M U$ & 2.8 & 2.2 & 3.5 & + & $N$ \\
\hline 23 & 109/F & + & 49.1 & ND & Homo & ND & $\mathrm{ROI}(\mathrm{m})$ & 8.4 & 0 & $M U$ & 4.3 & $U$ & 4.6 & 2.8 & 0.5 & + & M \\
\hline 24 & $12 / M$ & - & 56.3 & ND & Hetero & $\mathrm{ROI}$ & $\mathrm{ROI}(\mathrm{m}, \mathrm{p})$ & 7.4 & 0 & MU & 13.2 & U & 4.6 & 2.4 & 1.9 & + & M \\
\hline 25 & $15 / M$ & + & 55.9 & $\mathrm{ROH}$ & Hetero & $\mathrm{ROI}$ & $\mathrm{ROI}(\mathrm{m}, \mathrm{p})$ & 5.7 & 0 & $M U$ & 6.5 & $M U$ & 5.1 & 2.2 & 0 & + & ND \\
\hline 26 & $6 / M$ & UK & 51.1 & ND & Hetero & $\mathrm{ROI}$ & $\mathrm{ROI}(\mathrm{m}, \mathrm{p})$ & 5.6 & 0.1 & MU & 4.7 & $U$ & 1.2 & 0.5 & 2.7 & + & ND \\
\hline 27 & $10 / M$ & + & 62.1 & $\mathrm{ROH}$ & Homo & ND & $\mathrm{ROI}(\mathrm{m})$ & 5 & 0 & $M U$ & 0.9 & U & 5 & 1.1 & 0 & - & ND \\
\hline 28 & $29 / \mathrm{F}$ & + & 61.5 & ND & Homo & ND & $\mathrm{ROI}(\mathrm{m})$ & 3.7 & 0 & $M U$ & 1.5 & $M U$ & 2.5 & 1.4 & 2.5 & + & $M$ \\
\hline 29 & $26 / M$ & + & 55.4 & ND & Homo & ND & $\mathrm{ROI}(\mathrm{m})$ & 3.1 & 0.2 & $M U$ & 9.3 & $M U$ & 0.4 & 1.2 & 0.7 & - & $M$ \\
\hline 30 & $18 / M$ & + & 48.7 & ND & Hetero & $\mathrm{ROI}$ & $\mathrm{ROI}(\mathrm{m}, \mathrm{p})$ & 2.4 & 0.1 & MU & 1.2 & $M U$ & 1.1 & I & 0.8 & - & ND \\
\hline 31 & $13 / M$ & + & 55.3 & ND & Hetero & $\mathrm{ROI}$ & $\mathrm{ROI}(\mathrm{m}, \mathrm{p})$ & 2.2 & 0 & $M U$ & 1.1 & $M U$ & 1.5 & 1 & 0.6 & + & $\mathrm{N}$ \\
\hline 32 & $60 / F$ & + & 55.7 & ND & Hetero & $\mathrm{ROI}$ & $\mathrm{ROI}(\mathrm{m}, \mathrm{p})$ & 0.7 & 0.2 & MU & 0.2 & $M U$ & 0.3 & 0.9 & 0.4 & + & $N$ \\
\hline 33 & $29 / M$ & + & 56.4 & ND & Homo & ND & $\mathrm{ROI}(\mathrm{m})$ & 0.5 & 1 & MU & 0.1 & $M U$ & 0 & 0.5 & 1.2 & - & M \\
\hline 34 & $9 / M$ & + & 56.7 & ND & Hetero & $\mathrm{ROI}$ & $\mathrm{ROI}(\mathrm{m}, \mathrm{p})$ & 0.5 & 0 & $M U$ & 0 & $M U$ & 0.1 & 0.2 & 0.2 & + & M \\
\hline $35-54$ & $4-|56 / \mathrm{MI}|$, F9 & $+12,-7$, UKI & $41-65$ & $\mathrm{ROH}$ & ND & ND & $\mathrm{ROI}(\mathrm{m})$ & ND & ND & ND & ND & ND & ND & ND & ND & ND & MII, N9 \\
\hline Normal livers & & & 52.8 & ND & ND & ND & $\mathrm{ROI}(\mathrm{m})$ & 1 & 1 & MU & 1 & $M U$ & 1 & 1 & 1 & - & \\
\hline Fetal livers & & & ND & & ND & ND & ND & 5.9 & 0.2 & ND & 6.4 & ND & 4.8 & 1.9 & 2.4 & ND & \\
\hline $\mathrm{HuH6}$ & & & 87.3 & $\mathrm{ROH}$ & Hetero & LOI & $\mathrm{LOI}(\mathrm{m}, \mathrm{p})$ & 0 & 0 & $M U$ & 0 & $M U$ & 0 & 0.1 & 0 & + & M \\
\hline HepG2 & & & 89.5 & UPD & Homo & ND & UPD $(m)$ & 2.4 & 0 & $U$ & 1.5 & $U$ & 5 & 2.8 & 0 & + & $M$ \\
\hline
\end{tabular}

$\mathrm{F}=$ female; $\mathrm{M}=$ male; $\mathrm{M}=$ methylated; $\mathrm{ROH}=$ retention of heterozygosity; $\mathrm{ROI}=$ retention of imprinting; $\mathrm{U}=$ unmethylated; $\mathrm{ND}=$ not done; $U K=$ unknown. $\mathrm{All} 20$ tumours showed unmethylated promoter 4; UPD, uniparental

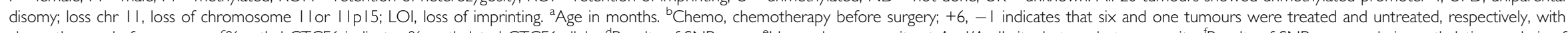
chemotherapy before surgery. \%methyl CTCF6 indicates \% methylated CTCF6 allele. 'Results of SNP array. ${ }^{e}$ Homo, homozygosity at Apal/Avall site; hetero, heterozygosity. ${ }^{\mathrm{f}}$ Results of SNP array analysis, methylation analysis of 

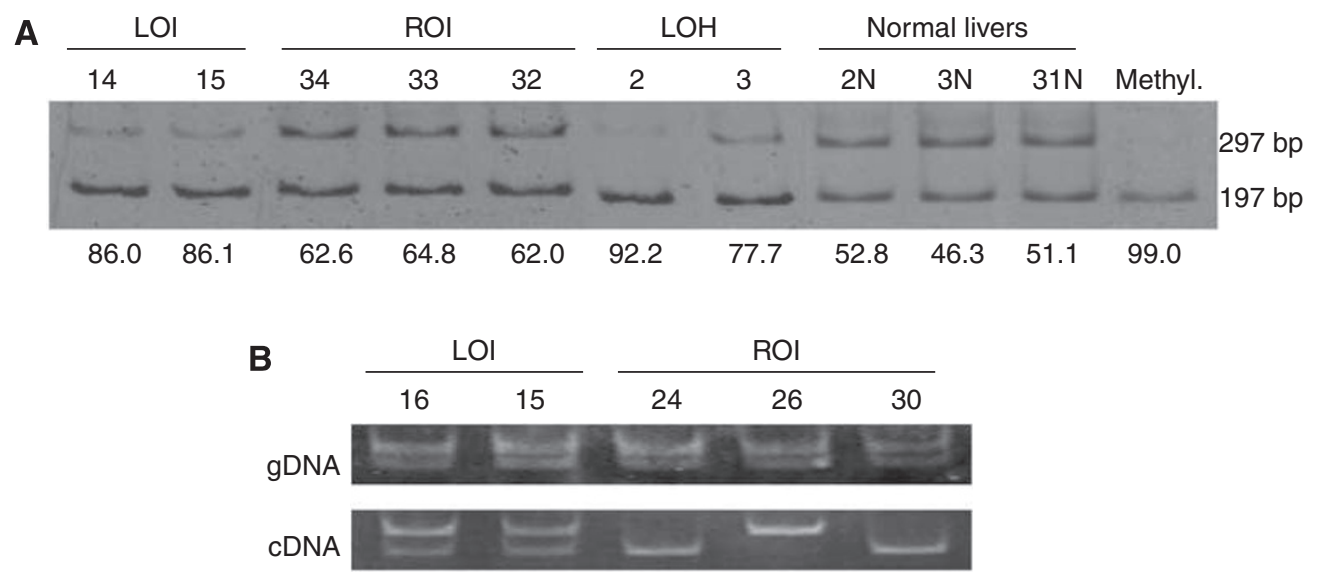

Figure I Analysis of IGF2 alterations. (A) Examples of the methylation status of CTCF6 analysed by a combined bisulphite restriction assay (COBRA). Bisulphite-modified PCR products were digested with Mlul. Upper and lower lanes indicate unmethylated and methylated fragments, respectively. Numbers above lanes indicate the tumour number. Numbers below lanes show the percentage of methylated DNA fragments containing CTCF6. The mean value of the DNA methylation percentages calculated from three COBRA experiments is shown in Table I. Methyl., control methylated DNA. The IGF2 status is shown above the tumour numbers. LOI, loss of IGF2 imprinting; LOH, loss of heterozygosity in the IGF2 region; ROI, retention of IGF2 imprinting. (B) Electrophoretic pattern of genomic DNA PCR products or RT-PCR products after Avall digestion. Reverse transcriptase-PCR analysis shows LOI in two tumours and $\mathrm{ROI}$ in three tumours.

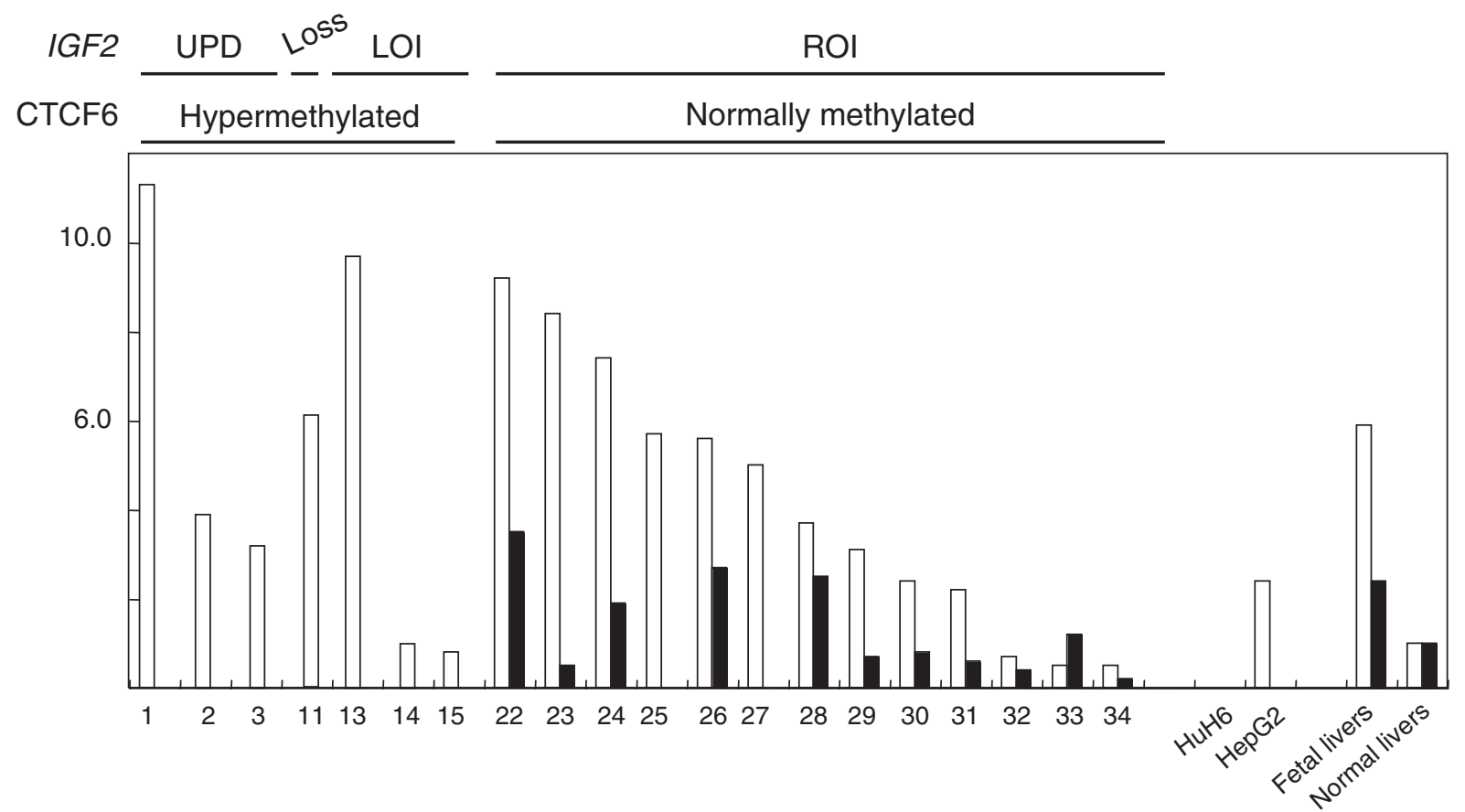

Figure 2 Results of quantitative real-time RT-PCR analysis of IGF2 and HI9 mRNAs. Relative mRNA (Y axis) of total IGF2 (open rectangles) and HI 9 (closed rectangles) is plotted in 3 tumours with UPD, in I tumour with I I I 5 loss, in 3 tumours with LOI, in I 3 tumours with ROI, in 2 cell lines, in foetal liver total RNA and in adjacent normal liver tissues (a mean value of 3 samples). Tumours in each group are arranged in order by the levels of IGF2 mRNA. Numbers below $X$ axis indicate the tumour number shown in Table I. IGF2 status (UPD, loss of I I I I, LOI and ROI) and methylation status of CTCF6 at HI9 DMR (hypermethylated or normally methylated) are shown above the graph. Nine tumours (nos. I -3, II, I3- I5, 25 and 27) and two cell lines expressed a minimal amount of HI 9 mRNA, which was shown as zero in the graph. Similarly, HuH6 expressed a minimal amount of IGF2 mRNA, which was shown as zero in the graph.

\section{Incidences of tumours with CTNNB1 mutation between any two groups of tumours classified on the basis of the IGF2 status}

DNA was available for CTNNB1 mutation analysis in 48 of $54 \mathrm{HB}$ tumours. The results are described in Table 1 . There were no differences in the incidences of CTNNB1 mutation between 7 tumours with IGF2-LOI and 29 tumours with IGF2-ROI or 12 tumours with IGF2-LOH, and between 29 tumours with IGF2-ROI and 12 tumours with IGF2-LOH.

\section{DISCUSSION}

In this study, biallelic and monoallelic IGF2 expressions correlated with hypermethylation and normal methylation of CTCF6, 
A

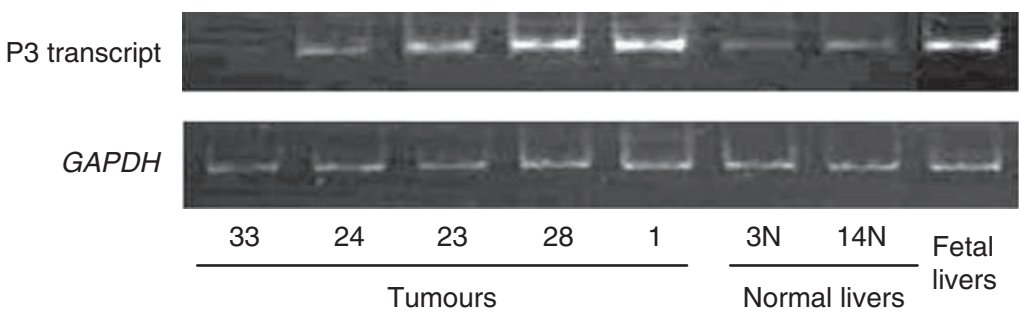

C Total IGF2 mRNA/GAPDH

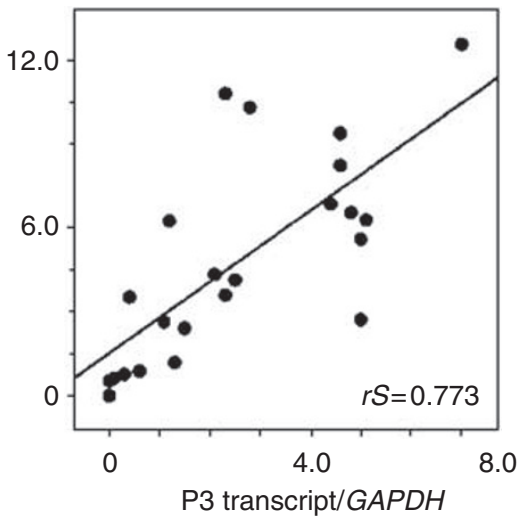

B

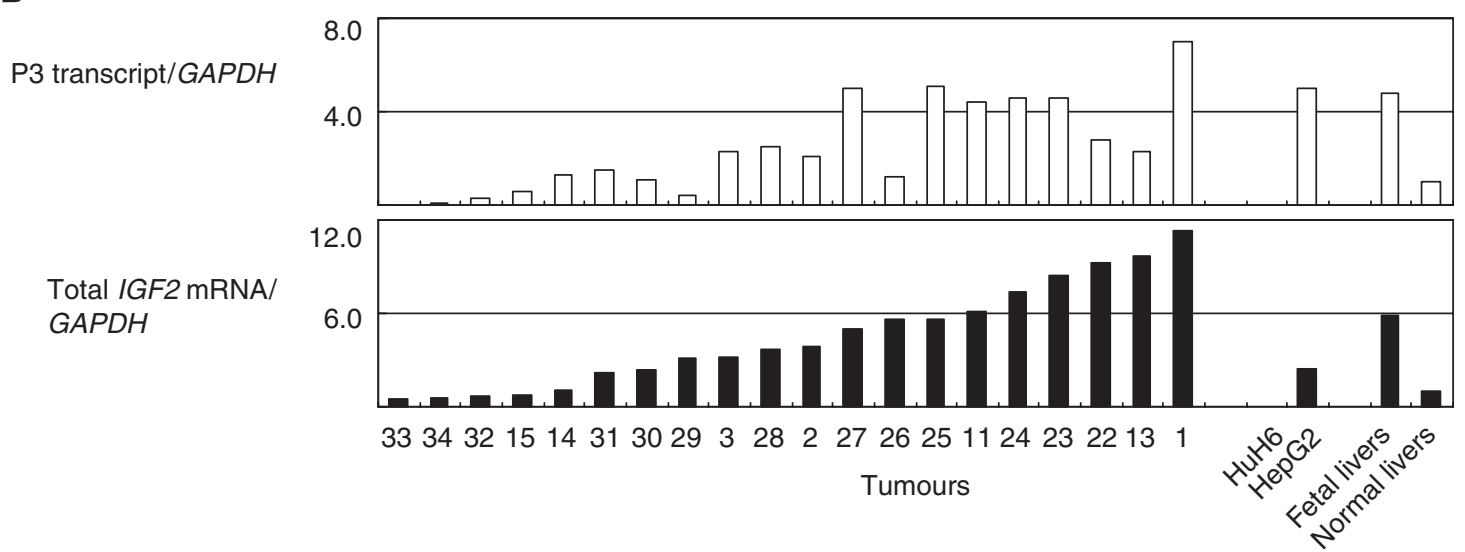

Figure 3 (A) Representative data of RT-PCR analysis of P3 transcripts. (B) Expression levels of P3 transcripts (upper lane) and total IGF2 mRNA (lower lane) are plotted in 20 tumours, in 2 cell lines, in foetal liver tissues and normal liver tissues (a mean value of 3 samples). Tumours are arranged in order by total levels of IGF2 mRNA. Numbers below $X$ axis indicate the tumour number. (C) Correlation between levels of P3 transcript ( $X$ axis) and total IGF2 mRNA (Y axis).

respectively, in two tumours with LOI and seven tumours with ROI (Table 1, Figure 1). In addition, the paternal origin of the duplicated IGF2 loci was confirmed by the hypermethylated CTCF6 in 10 tumours with UPD. Furthermore, very low expression levels of $H 19$ mRNAs and substantial expression levels of IGF2 mRNAs in HB tumours with UPD or LOI, and substantial expression levels of both IGF2 and H19 mRNA in HB tumours with ROI were found (Table 1 and Figure 2). Two (nos. 14 and 15) of three HB tumours with LOI expressed IGF2 mRNA levels comparable to but not higher than those of IGF2 mRNA in normal liver tissues. In addition, one cell line, HuH6, with LOI expressed minimal expression of IGF2 mRNA, although Hartmann et al (2000) found the moderate expression in the same cell line. These findings may be explained by the speculation that such tumours expressed increased levels of IGF2 mRNA at the critical time of tumorigenesis, but not at the time of surgical resection or after many passages of cell culture. From these findings, the hypothesis established for WT that the hypermethylation of maternal H19 DMR causes LOI, and that LOI or duplication of paternal IGF2 (UPD) results in overexpression of IGF2, may be also applied to HB.

Although the expression levels of IGF2 mRNA were reported to be higher in WTs with UPD than in WTs with ROI in two series of WTs (Wang et al, 1996; Haruta et al, 2008), conflicting results were reported in IGF2 mRNA levels between WTs with LOI and WTs with ROI (Wang et al, 1996; Ravenel et al, 2001). The present and earlier studies showed that all HB tumours with UPD and the majority of $\mathrm{HB}$ tumours with LOI or ROI expressed the higher levels of IGF2 mRNA than normal liver tissues (Li et al, 1998b; Gray et al, 2000; Hartmann et al, 2000). This study also showed that P3 transcripts predominated in total IGF2 mRNAs in HB tumours irrespective of the IGF2 status (i.e., UPD, $11 \mathrm{p} 15$ loss, LOI or ROI); these findings were similar to those reported in foetal liver tissues showing elevated expression of IGF2 mRNA with predominance of the P3 transcript (Li et al, 1998a). Thus, the high IGF2 mRNA expression of many HB tumours with ROI may mimic the upregulation of IGF2 expression in embryonic liver tissues, from which $\mathrm{HB}$ may arise.

In this study of $54 \mathrm{HB}$ tumours, we found $\mathrm{LOH}$ in $12(22.2 \%)$, LOI in $9(16.7 \%)$ and ROI in $33(61.1 \%)$. Hepatoblastoma tumours can be classified into those with $\mathrm{LOH}$ and those with $\mathrm{ROH}$, and tumours with $\mathrm{ROH}$ can be further classified into those with LOI and those with ROI. For data comparison, the frequencies of $\mathrm{LOH}$ and LOI in the earlier and present series of HB tumours are shown in Tables 2 and 3, respectively (Davies, 1993; Montagna et al, 1994; Li et al, 1995; Rainier et al, 1995; Fukuzawa et al, 1999; Gray et al, 2000; Hartmann et al, 2000; Ross et al, 2000; Albrecht et al, 2004; Suzuki et al, 2008). Both frequencies of LOH and LOI were similar between the earlier and present series of HB tumours. When we compared the frequencies of $\mathrm{LOH}$ and LOI between $\mathrm{HB}$ and WT, the frequencies of $\mathrm{LOH}$ and LOI are lower in HB tumours than in WT tumours (Table 4). The present and earlier studies showed that levels of IGF2 mRNA are higher in normal liver tissues than in normal kidney tissues, and in foetal liver tissues than in foetal kidney tissues, but showed similarly high levels in both WTs and HBs (part of the data not shown) (Hedborg et al, 1994; Haruta 


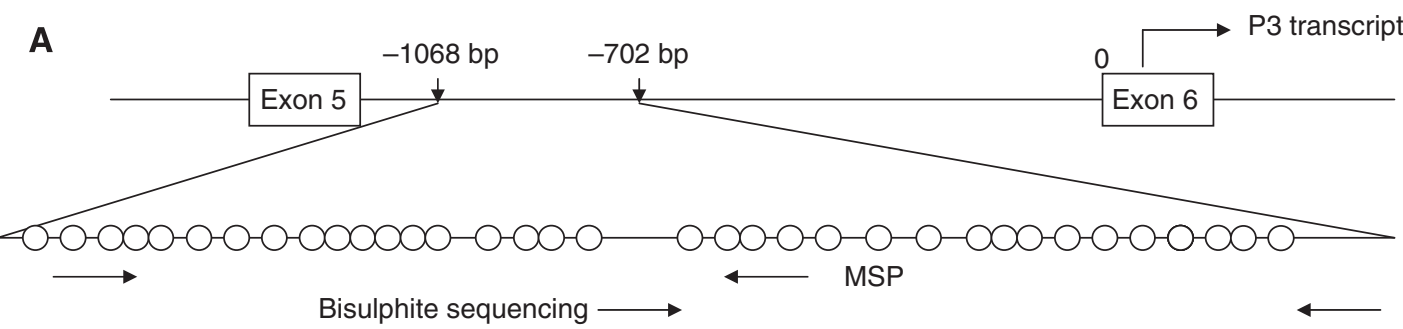

B

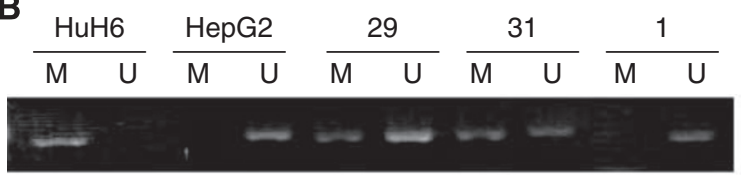

C HuH6

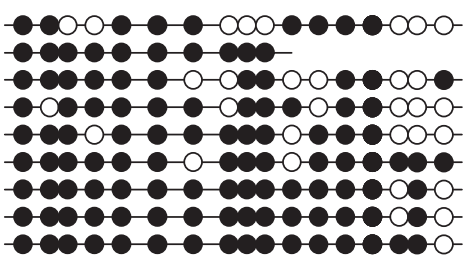

1

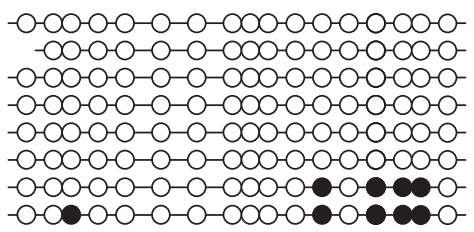

D

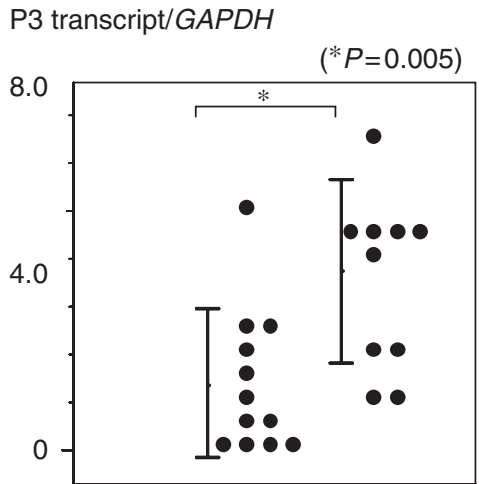

Partially Methylated

Figure 4 (A) Diagram of the IGF2 P3 promoter region. Individual CpG dinucleotides located upstream of exon 6 (from - I068 to -702 bp) are represented by circles. Horizontal arrows indicate locations of PCR primers used for MSP and bisulphite sequencing. (B) Examples of the promoter methylation status using methylation-specific PCR. Polymerase chain reaction products of methylated or unmethylated P3 promoters from HB tumours are shown. Numbers above horizontal bars indicate the tumour number. $M$, methylated promoter; $U$, unmethylated promoter. (C) Bisulphite sequencing analysis of the methylation status of P3 promoter in $\mathrm{HuH} 6$ and one tumour (no. I), which displayed complete methylation and complete unmethylation, respectively. Open and closed circles indicate unmethylated and methylated CpG dinucleotides, respectively. (D) Levels of P3 transcripts in tumours with partially methylated P3 promoter and tumours with unmethylated P3 promoter.

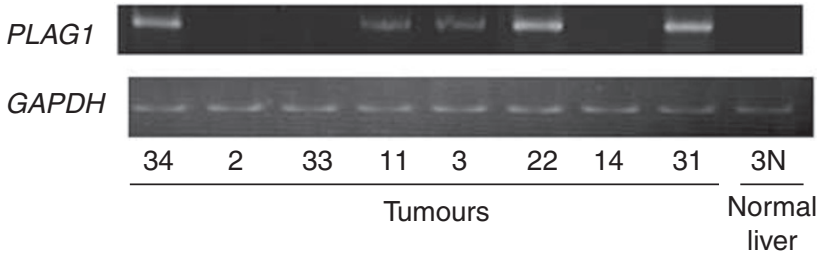

Figure 5 Representative data of RT-PCR analysis of PLAGI mRNA. Numbers below lanes indicate the tumour number.

et al, 2008), indicating that embryonal kidney tissues might be more susceptible to IGF2 stimulation than embryonal liver tissues. These findings might be related to higher incidences of UPD or LOI in WT than in HB.

The IGF2 gene has four promoter regions and each promoter can initiate transcription producing a distinct IGF2 transcript with different $5^{\prime}$-untranslated regions with a common translated region in the $3^{\prime}$-side ( $\mathrm{Li}$ et al, 1998a). The IGF2 gene is transcriptionally regulated in a development-dependent and tissue-specific manner. In the foetal liver, promoters $\mathrm{P} 2, \mathrm{P} 3$, and $\mathrm{P} 4$ are active and expressed monoallelically; $\mathrm{P} 3$ is the most active promoter and $\mathrm{P} 1$ is inactive. However, in the adult liver, $\mathrm{P} 1$ becomes dominant and is biallelically expressed, and P2, P3 and P4 activities are decreased or lost ( $\mathrm{Li}$ et al, 1998a). In foetal liver tissues, P3 promoter methylation is inversely correlated with the P3 transcript expression. The inverse correlation between $\mathrm{P} 3$ promoter methylation and P3 transcript expression was reported earlier in seven $\mathrm{HB}$ tumours (Li et al, 1998b). This study confirmed the upregulation of P2, P3 and P4 transcripts and downregulation of P1 transcript, and
Table 2 Incidences of LOH of IGF2 in previous and present series of hepatoblastoma and Wilms' tumours

\begin{tabular}{lcccc}
\hline References & $\begin{array}{c}\text { Total } \\
\text { number }\end{array}$ & $\begin{array}{c}\text { LOH of } \\
\text { IGF2 }^{\mathbf{a}}\end{array}$ & $\begin{array}{c}\text { No-LOH } \\
\text { of IGF2 }\end{array}$ & $\%$ \\
\hline Hepatoblastoma & & & & \\
$\quad$ Montagna et al (1994) & 13 & 3 & 10 & 23.1 \\
Fukuzawa et al (1999) & 7 & 2 & 5 & 28.6 \\
Gray et al (2000) & 10 & 2 & 8 & 20.0 \\
Hartmann et al (2000) & 24 & 6 & 18 & 25.0 \\
Albrecht et al (2004) & 56 & 13 & 43 & 23.2 \\
Suzuki et al (2008) & 17 & 4 & 13 & 23.5 \\
Total number & 127 & 30 & 97 & 23.6 \\
Present study & 54 & 12 & 42 & 22.2 \\
Wilms' tumour & & & & \\
Grundy et al (1996) & 260 & 93 & 167 & 35.8 \\
Yuan et al (2005) & 62 & 26 & 36 & 41.9 \\
\hline
\end{tabular}

${ }^{a}$ Tumours with $\mathrm{LOH}$ of I Ip I5, but no informative IGF2 locus are included.

the inverse correlation between $\mathrm{P} 3$ promoter methylation and $\mathrm{P} 3$ transcript expression in the majority of $20 \mathrm{HB}$ tumours. Although $\mathrm{P} 2, \mathrm{P} 3$ and $\mathrm{P} 4$ transcripts were all correlated to the total amount of IGF2 mRNAs, the earlier and present studies showed that the P3 transcript was most abundant and seemed to play a major role in the tumorigenesis of $\mathrm{HB}$ ( $\mathrm{Li}$ et al, 1998b). Increased IGF2 expression with the predominant $\mathrm{P} 3$ transcript was reported earlier in WTs with LOI or ROI (Vu and Hoffman, 1999). This study also showed that HB tumours with hypermethylated $\mathrm{H} 19$ DMR tended to have an unmethylated $\mathrm{P} 3$ promoter, indicating that 
Table 3 Incidences of LOI of IGF2 in previous and present series of hepatoblastoma and Wilms' tumours

\begin{tabular}{lcccc}
\hline References & Total number & LOI of IGF2 & ROI of IGF2 & $\%$ \\
\hline Hepatoblastoma & 3 & 0 & 3 & 0 \\
$\quad$ Davies (1993) & 5 & 1 & 4 & 20.0 \\
Montagna et al (1994) & 5 & 1 & 4 & 20.0 \\
Rainier et al (1995) & 3 & 1 & 2 & 33.3 \\
Li et al (1995) & 4 & 1 & 3 & 25.0 \\
Fukuzawa et al (1999) & 13 & 3 & 10 & 23.1 \\
Ross et al (2000) & 5 & 3 & 2 & 60.0 \\
$\quad$ Hartmann et al (2000) & 38 & 10 & 28 & 26.3 \\
Total number & 42 & 9 & 33 & 21.4 \\
Present study & & & & \\
Wilms' tumour & 36 & 15 & 21 & 41.7 \\
Ravenel et al (200I) & 29 & 22 & 7 & 75.9 \\
Yuan et al (2005) & & &
\end{tabular}

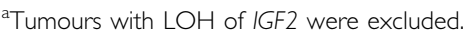

the paternal P3 promoter or the maternal P3 promoter upstream of the aberrantly methylated H19 DMR is likely to be unmethylated, probably because of stimulation of the enhancer signal. In contrast, the significance of unmethylation in the P3 promoter found in 4 (nos. 23, 24, 26 and 27) of $13 \mathrm{HB}$ tumours with normally methylated H19 DMR (ROI) remains unresolved.

PLAG1 located in 8q11 encodes a developmentally regulated transcription factor, and positively regulates IGF2. The P3 promoter region of IGF2 contains PLAG1 consensus-binding sites, and PLAG1 transactivates the transcription from embryonic IGF2 promoter P3 in HB cell lines, HuH6 and HepG2 (Zatkova et al, 2004). PLAG1 mRNA was highly expressed in most HB tumours compared with normal liver tissues. In this study, HB tumours with PLAG1 mRNA expression showed and tended to show higher levels of P4 and P3 transcripts, respectively. Thus, the correlation of PLAG1 mRNA expression with increased levels of P3 transcripts reported by Zatkova et al (2004) may be confirmed; furthermore, the correlation of PLAG1 mRNA expression with increased levels of $\mathrm{P} 4$ transcripts was also suggested.

WTs can be classified at least into two groups; one has intralobar nephrogenic rest that is associated with WT1 abnormality and the other has perilobar nephrogenic rest associated with IGF2-LOI (Ravenel et al, 2001). CTNNB1 mutation is frequently found in WTs with WT1 abnormality, but rare in WTs without WT1 abnormality (Maiti et al, 2000). These findings suggest that WTs with no WT1 abnormality may include a substantial number
Table 4 Incidences of LOH, LOI and ROI of IGF2 in hepatoblastoma and Wilms' tumours

\begin{tabular}{lcccc}
\hline References & $\begin{array}{c}\text { Total } \\
\text { number }\end{array}$ & $\begin{array}{c}\text { LOH of } \\
\text { IGF2 }\end{array}$ & $\begin{array}{c}\text { LOI of } \\
\text { IGF2 }\end{array}$ & $\begin{array}{c}\text { ROI of } \\
\text { IGF2 }\end{array}$ \\
\hline $\begin{array}{l}\text { Hepatoblastoma } \\
\quad \text { Present study }\end{array}$ & 54 & $12(22.2 \%)$ & $9(16.7 \%)$ & $33(61.1 \%)$ \\
& & & & \\
$\begin{array}{l}\text { Wilms' tumour } \\
\quad \text { Fukuzawa et al (2004) }\end{array}$ & 41 & $17(41.5 \%)$ & $13(31.7 \%)$ & $11(26.8 \%)$ \\
$\quad$ Yuan et al (2005) & 58 & $29(50.0 \%)$ & $22(37.9 \%)$ & $7(12.1 \%)$ \\
\hline
\end{tabular}

of tumours with IGF2-LOI, and that CTNNB1 mutation and IGF2LOI may be mutually exclusive in WT and also in HB. However, there were no differences in the incidences of CTNNB1 mutation between HBs with IGF2-LOI and those with IGF2-ROI, or those with IGF2-LOH. We have recently reported a paper describing the occurrence of duplication of paternal IGF2 or IGF2-LOI in half of WTs with WT1 abnormalities (Haruta et al, 2008). Of two WTs with IGF2-LOI and WT1 abnormality reported in that paper, one had CTNNB1 mutation and the other had not. These findings suggest that CTNNB1 mutation and IGF2-LOI may not be mutually exclusive in either WT or HB.

The IGF signalling pathway is activated in various cancers, and monoclonal antibodies targeting IGF1R have been recently developed; IGF1R is a transmembrane tyrosine kinase receptor, and both IGF1 and IGF2 are ligands for IGF1R (Foulstone et al, 2005). Early clinical trials using anti-IGF1R monoclonal antibodies showed promising results in refractory Ewing's sarcomas and rhabdomyosarcomas (Ryan and Goss, 2008). Because $20-30 \%$ of $\mathrm{HB}$ tumours do not respond to the current chemotherapy consisting of cisplatin and adriamycin (Perilongo et al, 2000; Fuchs et al, 2002), and the great majority of HB tumours overexpresses IGF2, as shown in the present and earlier studies, HB may be the next target tumour for antibody therapy.

\section{ACKNOWLEDGEMENTS}

This study was supported by Ministry of Health, Labor and Welfare, Japan for Third-Term Comprehensive Control Research for Cancer ( $\mathrm{Y}$ Kaneko). We are grateful to Dr K Hiyama, Hiroshima University, a data administrator for JPLT, for data management. We also express our gratitude to the physicians participating in JPLT who supplied samples for this study.

\section{REFERENCES}

Albrecht S, Hartmann W, Houshdaran F, Koch A, Gärtner B, Prawitt D, Zabel BU, Russo P, Von Schweinitz D, Pietsch T (2004) Allelic loss but absence of mutations in the polyspecific transporter gene $B W R 1 A$ on 11p15.5 in hepatoblastoma. Int J Cancer 111: 627-632

Beeghly AC, Katsaros D, Wiley AL, Rigault de la Longrais IA, Prescott AT, Chen H, Puopolo M, Rutherford TJ, Yu H (2007) IGF-II promoter methylation and ovarian cancer prognosis. J Cancer Res Clin Oncol 133: 713-723

Bell AC, Felsenfeld G (2000) Methylation of a CTCF-dependent boundary controls imprinted expression of the Igf2 gene. Nature 405: 482-485

Davies SM (1993) Maintenance of genomic imprinting at the IGF2 locus in hepatoblastoma. Cancer Res 53: $4781-4783$

Foulstone E, Prince S, Zaccheo O, Burns JL, Harper J, Jacobs C, Church D, Hassan $\mathrm{AB}$ (2005) Insulin-like growth factor ligands, receptors, and binding proteins in cancer. J Pathol 205: 145-153

Fuchs J, Rydzynski J, Von Schweinitz D, Bode U, Hecker H, Weinel P, Bürger D, Harms D, Erttmann R, Oldhafer K, Mildenberger H (2002)
Pretreatment prognostic factors and treatment results in children with hepatoblastoma. Cancer 95: $172-182$

Fukuzawa R, Breslow NE, Morison IM, Dwyer P, Kusafuka T, Kobayashi Y, Becroft DM, Beckwith JB, Perlman EJ, Reeve AE (2004) Epigenetic differences between Wilms' tumours in white and East-Asian children. Lancet 363: $446-451$

Fukuzawa R, Umezawa A, Ochi K, Urano F, Ikeda H, Hata J (1999) High frequency of inactivation of the imprinted $H 19$ gene in 'sporadic' hepatoblastoma. Int J Cancer 82: 490-497

Gray SG, Eriksson T, Ekström C, Holm S, von Schweinitz D, Kogner P, Sandstedt B, Pietsch T, Ekström TJ (2000) Altered expression of members of the IGF-axis in hepatoblastomas. $\mathrm{Br} J$ Cancer 82: $1561-1567$

Grundy P, Telzerow P, Moksness J, Breslow NE (1996) Clinicopathologic correlates of loss of heterozygosity in Wilms' tumors: a preliminary analysis. Med Pediatr Oncol 27: 429-433 
Hark AT, Schoenherr CJ, Katz DJ, Ingram RS, Levorse JM, Tilghman SM (2000) CTCF mediates methylation-sensitive enhancer-blocking activity at the H19/Igf2 locus. Nature 405: 486-489

Hartmann W, Waha A, Koch A, Goodyer CG, Albrecht S, von Schweinitz D, Pietsch T (2000) $p 57^{K I P 2}$ is not mutated in hepatoblastoma but shows increased transcriptional activity in a comparative analysis of the three imprinted genes $p 57^{K I P 2}, I G F 2$, and H19. Am J Pathol 157: $1393-1403$

Haruta M, Arai Y, Sugawara W, Watanabe N, Honda S, Ohshima J, Soejima H, Nakadate H, Okita H, Hata J, Fukuzawa M, Kaneko Y (2008) Duplication of paternal IGF2 or loss of maternal IGF2 imprinting occurs in half of Wilms tumors with various structural WT1 abnormalities. Genes Chromosomes Cancer 47: 712-727

Hedborg F, Holmgren L, Sandstedt B, Ohlsson R (1994) The cell typespecific IGF2 expression during early human development correlates to the pattern of overgrowth and neoplasia in the Beckwith-Wiedemann syndrome. Am J Pathol 145: 802-817

Herman JG, Graff JR, Myöhänen S, Nelkin BD, Baylin SB (1996) Methylation-specific PCR: a novel PCR assay for methylation status of CpG islands. Proc Natl Acad Sci USA 93: 9821 - 9826

Honda S, Haruta M, Sugawara W, Sasaki F, Ohira M, Matsunaga T, Yamaoka H, Horie H, Ohnuma N, Nakagawara A, Hiyama E, Todo S, Kaneko Y (2008) The methylation status of RASSF1A promoter predicts responsiveness to chemotherapy and eventual cure in hepatoblastoma patients. Int J Cancer 123: $1117-1125$

Koch A, Denkhaus D, Albrecht S, Leuschner I, Von Schweinitz D, Pietsch T (1999) Childhood hepatoblastomas frequently carry a mutated degradation targeting box of the $\beta$-catenin gene. Cancer Res 59: 269-273

Li X, Adam G, Cui H, Sandstedt B, Ohlsson R, Ekström TJ (1995) Expression, promoter usage and parental imprinting status of insulinlike growth factor II (IGF2) in human hepatoblastoma: uncoupling of IGF2 and H19 imprinting. Oncogene 11: $221-229$

Li X, Gray SG, Flam F, Pietsch T, Ekström TJ (1998a) Developmentaldependent DNA methylation of the IGF2 and H19 promoters is correlated to the promoter activities in human liver development. Int $J$ Dev Biol 42: $687-693$

Li X, Kogner P, Sandstedt B, Haas OA, Ekström TJ (1998b) Promoterspecific methylation and expression alterations of igf 2 and $h 19$ are involved in human hepatoblastoma. Int J Cancer 75: 176-180

Lu L, Katsaros D, Wiley A, Rigault de la Longrais IA, Puopolo M, Schwartz P, Yu H (2006) Promoter-specific transcription of insulin-like growth factor II in epithelial ovarian cancer. Gynecol Oncol 103: 990-995

Maiti S, Alam R, Amos CI, Huff V (2000) Frequent association of $\beta$-catenin and WT1 mutations in Wilms tumors. Cancer Res 60: 6288-6292

Matsunaga T, Sasaki F, Ohira M, Hashizume K, Hayashi A, Hayashi Y, Matsuyama K, Mugishima H, Ohnuma N (2004) The role of surgery in the multimodal treatment for hepatoblastomas. Shounigan 41: 205-210 (in Japanese)

Montagna M, Menin C, Chieco-Bianchi L, D'Andrea E (1994) Occasional loss of constitutive heterozygosity at $11 \mathrm{p} 15.5$ and imprinting relaxation of the IGFII maternal allele in hepatoblastoma. J Cancer Res Clin Oncol 120: $732-736$

Perilongo G, Shafford EA (1999) Liver tumours. Eur J Cancer 35: 953-958 Perilongo G, Shafford S, Plaschkes J (2000) SIOPEL trials using preoperative chemotherapy in hepatoblastoma. Lancet Oncol 1: 94-100

Rainier S, Dobry CJ, Feinberg AP (1995) Loss of imprinting in hepatoblastoma. Cancer Res 55: 1836-1838

Ravenel JD, Broman KW, Perlman EJ, Niemitz EL, Jayawardena TM, Bell DW, Haber DA, Uejima H, Feinberg AP (2001) Loss of imprinting of insulin-like growth factor-II (IGF2) gene in distinguishing specific biologic subtypes of Wilms tumor. J Natl Cancer Inst 93: 1698-1703

Ross JA, Radloff GA, Davies SM (2000) H19 and IGF-2 allele-specific expression in hepatoblastoma. Br J Cancer 82: 753-756

Ryan PD, Goss PE (2008) The emerging role of the insulin-like growth factor pathway as a therapeutic target in cancer. Oncologist 13: 16-24

Satoh Y, Nakagawachi T, Nakadate H, Kaneko Y, Masaki Z, Mukai T, Soejima H (2003) Significant reduction of WT1 gene expression, possibly due to epigenetic alteration in Wilms' tumor. J Biochem 133: $303-308$

Steenman MJ, Rainier S, Dobry CJ, Grundy P, Horon IL, Feinberg AP (1994) Loss of imprinting of IGF2 is linked to reduced expression and abnormal methylation of H19 in Wilms tumor. Nat Genet 7: 433-439

Sugawara W, Haruta M, Sasaki F, Watanabe N, Tsunematsu Y, Kikuta A, Kaneko Y (2007) Promoter hypermethylation of the RASSF1A gene predicts the poor outcome of patients with hepatoblastoma. Pediatr Blood Cancer 49: 240-249

Suzuki M, Kato M, Yuyan C, Takita J, Sanada M, Nannya Y, Yamamoto G, Takahashi A, Ikeda H, Kuwano H, Ogawa S, Hayashi Y (2008) Wholegenome profiling of chromosomal aberrations in hepatoblastoma using high-density single-nucleotide polymorphism genotyping microarrays. Cancer Sci 99: 564-570

Takai D, Gonzales FA, Tsai YC, Thayer MJ, Jones PA (2001) Large scale mapping of methylcytosines in CTCF-binding sites in the human H19 promoter and aberrant hypomethylation in human bladder cancer. Hum Mol Genet 10: 2619-2626

Taniguchi K, Roberts LR, Aderca IN, Dong X, Qian C, Murphy LM, Nagorney DM, Burgart LJ, Roche PC, Smith DI, Ross JA, Liu W (2002) Mutational spectrum of beta-catenin, AXIN1, and AXIN2 in hepatocellular carcinomas and hepatoblastomas. Oncogene 21: $4863-4871$

Toretsky JA, Helman LJ (1996) Involvement of IGF-II in human cancer. I Endocrinol 149: $367-372$

Vu TH, Hoffman AR (1999) Alterations in the promoter-specific imprinting of insulin-like growth factor-II gene in Wilms tumor. J Biol Chem 271: 9014-9023

Wang WH, Duan JX, Vu TH, Hoffman AR (1996) Increased expression of the insulin-like growth factor-II gene in Wilms' tumor is not dependent on loss of genomic imprinting or loss of heterozygosity. J Biol Chem 271: $27863-27870$

Watanabe N, Haruta M, Soejima H, Fukushi D, Yokomori K, Nakadate H, Okita H, Hata J, Fukuzawa M, Kaneko Y (2007) Duplication of the paternal IGF2 allele in trisomy 11 and elevated expression levels of IGF2 mRNA in congenital mesoblastic nephroma of the cellular or mixed type. Genes Chromosomes Cancer 46: 929-935

Watanabe N, Nakadate H, Haruta M, Sugawara W, Sasaki F, Tsunematsu Y, Kikuta A, Fukuzawa M, Okita H, Hata J, Soejima H, Kaneko Y (2006) Association of $11 \mathrm{q}$ loss, trisomy 12, and possible $16 \mathrm{q}$ loss with loss of imprinting of insulin-like growth factor-II in Wilms tumor. Genes Chromosomes Cancer 45: 592-601

Yuan E, Li CM, Yamashiro DJ, Kandel J, Thaker H, Murty VV, Tycko B (2005) Genomic profiling maps loss of heterozygosity and defines the timing and stage dependence of epigenetic and genetic events in Wilms' tumors. Mol Cancer Res 3: 493-502

Zatkova A, Rouillard JM, Hartmann W, Lamb BJ, Kuick R, Eckart M, von Schweinitz D, Koch A, Fonatsch C, Pietsch T, Hanash SM, Wimmer K (2004) Amplification and overexpression of the IGF2 regulator PLAG1 in hepatoblastoma. Genes Chromosomes Cancer 39: $126-137$ 